\title{
In memory of Dr. José Geraldo Vernet Taborda (1951-2014)
}

\author{
Em memória do Dr. José Geraldo Vernet Taborda (1951-2014)
}

Juliana Fernandes Tramontina, ${ }^{1}$ Helena Dias de Castro Bins ${ }^{2}$

\begin{abstract}
In August 2014, the psychiatric community mourned the loss of an outstanding psychiatrist, professor, researcher, colleague, and friend, too. Dr. José Geraldo Vernet Taborda was among the most supportive and warmest of colleagues. He was a life enthusiast, and enjoyed each and every moment of life through his passion for psychiatry and spending moments with family and friends. Even in the last month, struggling against a cancer, Dr. Taborda had a full agenda committed to mentoring students, colleagues, and friends. He is survived by his wife, Maria Zenóbia; daughter, Maria Laura; and son, Julio Rafael.

Professor of Psychiatry and affiliated with the Graduate Program in Health Sciences at Universidade Federal de Ciências da Saúde de Porto Alegre (UFCSPA), Dr. Taborda first graduated in Legal and Social Sciences from Universidade Federal do Rio Grande do Sul (UFRGS), in 1974. Afterwards, he graduated in Medicine and completed his internship at the same renowned university, in 1983. He completed his psychiatry residency program at Pontifícia Universidade Católica do Rio Grande do Sul in 1986. Since then, Dr. Taborda was involved in forensic matters. He was also former professor of Medicine at UFRGS and at Universidade Luterana do Brasil (ULBRA), former director of the Institute of Criminal Biotypology (Department of Justice of the State of Rio Grande do Sul), and former director of the Criminological Observation Center (Department of Justice of the State of Rio Grande do Sul).
\end{abstract}

In his clinical activity, Dr. Taborda devoted himself to the treatment of adults and elderly. His practice was focused on patients with mood disorders, anxiety disorders, psychotic syndromes, posttraumatic stress disorder, and somatizers. In addition, he intensely studied the interface between general medical conditions and psychiatric disorders. Until his death, he was a medical staff member at Santa Casa de Misericórdia de Porto Alegre and Instituto de Cardiologia do Rio Grande do Sul, where he served as a psychiatric consultant.

His areas of special interest, research, and scientific production were primarily forensic psychiatry, bioethics, and medical ethics. He received a Master of Science degree in Medicine from UFRGS in 1996. His doctorate degree in Medicine was obtained in 2002, also in Medical Sciences from UFRGS. His doctoral dissertation was in the field of forensic psychiatry, related to the perception of coercion in psychiatric and nonpsychiatric (medical and surgical) inpatients.

Dr. Taborda's most influential published work describes the criminal justice system in Brazil. ${ }^{1}$ In that article, he discusses the concepts of dangerousness and penal responsibility, as well as the importance and functions of a forensic psychiatrist. Over the course of his career, he authored and coauthored over 80 articles, books, and book chapters on general psychiatry and forensic psychiatry. His magnificent book, written in cooperation with Dr. Abdalla-Filho and Dr. Chalub, entitled Forensic psychiatry, is considered one of the most important titles in the field in Brazil. ${ }^{2}$

\footnotetext{
${ }^{1}$ Psychiatrist. Professor, Universidade Federal de Ciências da Saúde de Porto Alegre, Porto Alegre, RS, Brazil. ${ }^{2}$ Forensic psychiatrist, Supreme Court of the State of Rio Grande do Sul, Porto Alegre, RS, Brazil. Financial support: none.

Suggested citation: Tramontina JF, Bins HD. In memory of Dr. José Geraldo Vernet Taborda (1951-2014). Trends Psychiatry Psychother. 2015;37(1):1-2. http://dx.doi.org/10.1590/2237-6089-2015-1001
} 
Few professors are as skilled as Dr. Taborda in inspiring students, whatever their academic level. His classes on deontological ethics were famous for his skills as a lecturer - his courses were always well attended.

Dr. Taborda was also a member of several professional societies. At the national (Brazilian) level, he was a member of the Academy of Medicine of Rio Grande do Sul (chair no. 56); of the Psychiatry Technical Chamber, Forensic Medical Board, Federal Council of Medicine; of the Brazilian Psychiatric Association; and of Associação de Psiquiatria do Rio Grande do Sul, the state's psychiatric association. Moreover, he founded the Bioethics and Legal Psychiatry Chapter of the Brazilian Psychiatric Association.

At the international level, he was a member of the most important organizations associated with psychiatry and law, namely, the American Academy of Psychiatry and the Law and the International Academy of Law and Mental Health. He was also member of the board of the World Psychiatric Association (WPA), serving as Regional Representative (Region 5). He was distinguished as Honorary Member of the WPA in the institution's world congress held in September 2011.

In the scientific publication scenario, Dr. Taborda served on the editorial boards of several forensic psychiatric journals, e.g., International Journal of Offender Therapy and Comparative Criminology (USA) and the International Journal of Forensic Mental Health (Canada).

At the university, he shouldered the responsibility as director of both the Psychiatric Forensic Residency Program and the General Psychiatric Residency Program at UFCSPA. He was also in charge of bioethics graduate courses and was coordinator of the Research Ethics Committee of the same institution.

With his talent, Dr. Taborda brightened Brazilian and international psychiatry in general and forensic psychiatry in particular. His passing is a tremendous loss to the field, and a deep personal loss to all of us who have known him. We are grateful to have had opportunities to learn and work with Dr. Taborda. We hope that we can sustain the same good energy level, responsibility, and happiness that Dr. Taborda showed us in his life.

As a tribute, this edition of Trends in Psychiatry and Psychotherapy features an article that still counted on the participation of Dr. José Geraldo Vernet Taborda.

\section{References}

1. Taborda JGV. Criminal justice system in Brazil: functions of a forensic psychiatrist. Int J Law Psychiatry. 2001;24:371-86.

2. Taborda JGV, Abdalla-Filho E, Chalub M. Psiquiatria forense. $2^{a}$ ed. Porto Alegre: Artmed; 2012. 